\title{
THE IMPACT OF ENVIRONMENTAL RESOURCE LEARNING APPLIED TO GEOMETRY IN EDUCATION FOR POWER AND CITIZENSHIP
}

\author{
Roosevelt Barros Morales ${ }^{1}$ (D), Mara Cabanilla Guerra ${ }^{2}$ D, Carlos Barros $^{2}$ (D), Sunny Bores Froment ${ }^{3}$ \\ ${ }^{1}$ Universidad de Guayaquil (Ecuador) \\ ${ }^{2}$ Universidad Tecnológica Empresarial de Guayaquil (Ecuador) \\ ${ }^{3}$ Grupo Compás (Ecuador) \\ roosevelt.barrosm@ug.edu.ec,mcabanilla@uteg.edu.ec,carlos_barros_b@hotmail.com,sbores@grupocompas.com
}

Received February 2018

Accepted March 2018

\section{Abstract}

This article is based on education for power and citizenship and related educational and social problems, where the axis of the issue is the environmental resources applied to learning geometry. These have a great impact on the teaching process, as it is currently considered that education should be interactive with respect to the environment. In recent years, the educational system has been able to perceive that, in scientific areas such as geometry, students have been limited to the role of receivers of conceptual contents from texts and websites, leaving aside the interaction by the learner with the surrounding environment. Studies using surveys conducted based on a Likert scale and administered with questions in simple language that is easily understood by the respondents have shown us that if the utility of environmental resources can be successfully merged with scientific areas, the result is greater knowledge acquisition and interest among students, especially in the area of geometry. This proposal is based on a change in the current educational model, employing a more attractive design, in which young people achieve greater proximity to subject being studied.

Keywords - Interactivity, Education, Enviroment.

\section{Introduction}

Education, power and citizenship require a society that is prepared in all aspects, but especially in the areas of logic and mathematics, and within these areas, geometry. The project is based on a current educational and social challenge that requires education to be interactive with regard to the education for the empowerment of human beings.

In recent years, the process used to teach geometry in the educational system, according to Espinoza, Barbé and Gálvez (2009) in their article, has been eroded by the little importance given to strategies that would pave the way to achieve knowledge; it is very common to observe that even though we live in the age of technology, traditional classes are still taught, based on content, leaving strategies for the power and citizenship of human beings in the background.

The educational system is intended to train human beings through teaching structures that formally organize their significant learning and the power of citizens who need caring, quality education to tackle the challenges that society presents on a daily basis at the different levels of knowledge, as defined by Singapore's Ministry of Education (2012). 
In the context of the proposed research, we envisage the importance of depicting this information to students at an upper basic level, as this is the stage at which the contents are evaluated with regard to the recognition of geometric shapes, since by this age bracket, the students have attained the motor functions and other needed skills to define, interpret and relate the theory to their environment. This article will provoke positive changes in education, because in the future we will have young students with developed criteria, capable of solving conflicts that are presented to them in daily life. This will also be a favorable change for the society in which they live.

One of the conflicts that has been presented in upper basic education with regard to the contents of geometry in education for power and citizenship is that they are presented to students as an entirely theoretical subject. This is a position with which Barber and Murshed do not agree (2007), indicating that the traditional teaching of this discipline has emphasized the memorization of formulas to calculate areas and volumes, as well as geometric definitions, theorems and properties, supported by out-of-context mechanistic constructions without the development of power.

For Espinoza, Barbé and Gálvez (2011), one of the situations demonstrating poor learning or pedagogical malpractice is associated with young people who acquire distorted or erroneous concepts, or in the worst-case scenario, who entirely lack these concepts. This causes serious problems in the learning process during later years of advanced studies. It is therefore important for teachers to keep in mind that the study of geometry is a description of and interaction with the space in which we live. In recent times, geometry has been considered to be a tool for understanding the social environment in which the cultural power of citizens prevails.

The limited strategies used by teachers trigger a lack of interest in the students to learn in any significant manner; these gaps are reflected in evaluations, although students also present difficulties in the use of technological tools. If the usefulness of the resources in their environment is not clear to them for the construction of geometric concepts, it becomes an unending source of educational obstacles that transform the learning of this subject into something lacking consistency and rigor. The failure to use other resources or materials that extend the students' conceptual scheme would represent an incomplete conception of the mathematical aim; the identification or construction of examples of a concept means that they must take into account the image of the concept (the student's mental reflection) and the definition of the concept (verbal), as well as those mental (e.g. logical schemas) or physical (e.g. shape rotations) operations in which a comparison with the mental image becomes easier.

The carrying out of this scientific work is justified by the importance of acquiring knowledge on geometry; it is obvious that if environmental resources are used as a cross-cutting theme, the learning will become much more significant and practical, as everything around us is symmetric and has composition and proportion. Accordingly, the students are not only acquiring a basic concept of geometry, but a culture of critical examination and synthesis is being awakened within them, rendering them capable of analyzing and synthesizing the world around them.

The general aim of applying this research is to identify the influence of the use of environmental resources on the learning of geometry in education for power and citizenship, through field research that makes it possible to obtain possible solutions to contribute to the development of better geometric concepts through recreational workshops.

The specific objectives are:

- To analyze the usefulness that students assign to resources in their environment.

- To list the shortcomings in the students' knowledge of geometry in education for power and citizenship.

- To indicate the fields of action in which it is necessary to rebuild knowledge on geometry through two recreational workshops: one targeting teachers and another for students, which are the basis for carrying out the project. 


\section{Development}

Geometry is one of the mathematical topics with the greatest importance for humanity and its development. It is directly or indirectly related to a number of activities that are carried out either for the progress of society, study or recreation. While it is true that the teaching of geometry in the educational setting corresponds, first of all, to the role geometry plays in the daily lives of students, with this being essential in order to live their daily lives, to orient themselves reflexively in space, to estimate shapes and distances, and to make estimates and calculations of the distribution of objects in space, it is also present in many different areas of the production system in our societies today (industrial production, design, architecture and topography).

The teaching of geometry has traditionally had a strongly deductive nature. In secondary education, geometry has been supported by the language of algebra in vector algebra. In primary education, albeit without this formal algebraic nature, excessive promotion has been placed in the memorization of concepts, theorems and formulas; the simple supporting of concepts on other previous ones; and the early elimination of intuition as an instrument to access geometric knowledge, in an attempt to accelerate the acquisition of these concepts, theorems and formulas, as if the true geometric knowledge was condensed within them.

On the other hand, in the context of the teaching of geometry, location in space is important, as through it skills are acquired that consolidate the theoretical concepts.

Brousseau (1997), in his article Theory of didactical situations in mathematics. Didactique des mathématiques, states that the spatial capacity of students is many times superior to their numerical skill, and fostering and improving this capacity, along with the mastery of geometric concepts and language, enables them to better learn the numerical ideas, those related to measurement and even other more advanced topics (Brousseau, 1997: page 3).

In this manner, the conjecture is solidified that the spatial development of students is better than their skill in calculating with numbers, which is why it is necessary to motivate and optimize positioning in space, linking it to the geometrical knowledge acquired in order to achieve significant learning.

On the other hand, Gertler, Martínez, Premand, Rawlings and Vermeersch (2011), and Artigue (2011) explain that the traditional model is subject to contradictory approximations: on the one hand, it constitutes the main way of conducting and representing the educational activity, an image in which the teacher lectures in a class according to the traditional transmission method (this apparent face of the educational work finds its history and reasons here), and on the other, the traditional model is often criticized and challenged.

In this regard, and in order to respond to many concerns, this article has been proposed with the purpose of planting the seed of a new learning paradigm in future generations, one that awakens in students an interest in and an appreciation for the importance of acquiring knowledge about geometry.

Research into the process of constructing geometric thought seems to indicate, however, that it evolves very slowly from some initial intuitive forms of thought to the final deductive forms, and that the latter correspond to levels of schooling that are quite a bit more advanced than those we are considering here. We thus understand that in Basic Education it is necessary to avoid deductivist interpretations in favor of a geometry of an experimental, intuitive nature. Young people's space is full of geometric elements, with a specific meaning for him or her: doors, windows, tables, balls, among others. In their daily environment, in their neighborhoods, homes, schools, recreational spaces, they learn to mentally organize the space surrounding them, to orient themselves in space.

Chevallard (2012) indicates that geometry is very important, since it allows us to teach and learn the art of reasoning, because it is abstract, but easy to visualize and it has many specific applications, such as calculating the area of a lot to fence, determining the volume of a soda can, building well-structured bridges, experimental stations in space, large sports coliseums, among others. 
Upon analyzing this, it is evident that if environmental resources are used as a cross-cutting theme, the learning will become much more significant and practical, because if we realize that everything around us is composed of symmetry, composition and proportion, we are not merely acquiring a basic concept of geometry, we are also awakening in students the culture of critical examination and synthesis, rendering them capable of analyzing and synthesizing the world around them.

Porlán, Rivero and Martín del Pozo (1998), and Cantoral (2014) sustain that the analysis of critical examination is a methodology that enables us to establish the hierarchy or priorities of processes, systems and equipment, creating a structure that facilitates making correct and effective decisions, directing effort and resources to the most important and/or necessary areas to improve operational reliability based on the current reality.

In light of the citations, it would seem that critical examination within the educational context is especially useful for developing geometric teachings in a way that is significant for students. The study of the nearby and familiar environment can awaken interest and motivation and is an inexhaustible source of objects susceptible to observation and manipulation of the citizen's power in his or her environment.

The point, as a dimensionless geometric entity, lacking shape or with a very regular (spherical) shape, as a simple indicator of position in space, does not exist in the material reality. In reality, all material beings have a size and shape: no matter how small we draw a point, it can always be divided into smaller parts; if we were to consider the spherical (or circular) point, these parts that are obtained by dividing it no longer have that spherical (or circular) shape. The straight line also does not exist in the material reality.

The notion of parallelism appears as a difficult notion for students, due to the infinite nature of the straight line. Students of these ages do not easily perceive the infinite nature of the straight line. This is first of all related to a problem of mental fixation derived from their own perceptions. Secondly, it is a problem of logical capacity, since students of these ages are in the stage Piaget calls "concrete logic", in which there is no room for the consideration of concepts as abstract as infinity. This same difficulty also arises when considering angles. It is not easy for them to understand the independence of the angle with regard to the length of its sides, first of all, due to matters of a perceptive nature, and second of all, due to the conceptual problem related to the infinity of the straight line, as indicated above.

American Institutes for Research (AIR) (2005), and Mullis, Martin, Foy and Arora (2012) propose that beyond mathematical contents, teachers in the early levels of basic education must keep in mind that "the most important thing is to cause children's minds to begin the thought process that leads to the creation of ideas and the verbal and symbolic expression of them". In this way, from the constructivist perspective, the teacher as the mediator of learning, is the one most called upon to provide the student with strategies with contextualized contents interrelated with the environment and that lead to achieving significant and permanent learning.

In reality, these examples serve to indicate the difficulty of teaching geometry in Upper Basic Education, due to the contradiction that exists between the strongly abstract nature of this subject (which like any mathematical discipline appears as an abstract conceptual system that is both formal and independent of the physical reality) and the need to introduce it to the students in an intuitive and experimental manner, which requires a simplification of its conceptual elements.

The instructional materials perform a crucial role in this teaching methodology. It is necessary to differentiate between the material intended to be used in the psychomotor sessions in a large, spacious classroom, and the material designed to be used in a normal classroom at the students' desks. With regard to the first type of material, we can first point out materials typical of psychomotor skills, such as ropes, rings, balls, paper, among others, that in addition to their specific value for psychomotor activities, are also of interest for developing geometric concepts. For example, ropes can be used to create lines, paths, networks, among others; rings can be used to form circumferences, cylinders or cones, for turning activities, among others; balls can be used to make spheres, for turning activities, for trajectory activities, 
among others; paper can be used to form different surface shapes, the faces of polyhedrons made from other materials, among others.

A structured material especially designed for these purposes is that of articulated polyhedrons and polygons. These are wooden rods of different lengths (varying from decimeter to decimeter, from one to ten, until reaching a meter), that can be joined by flexible or rigid joints. The flexible joints can be created by joining small pieces of rubber tubing together with a wire knot, connecting wooden rods to their openings to create the vertex of a polyhedric structure.

As complementary tabletop materials for classroom use, we can introduce, on the one hand, everyday materials (not necessarily mathematical), and on the other, materials especially designed for teaching geometry. Within the first type, we could cite sticks, wooden rods, ropes, wires, straws, clay, cork, among others, with which polygonal and polyhedric structures could also be made. As materials specifically for geometric use, we can mention basically the geoboard and polyhedron cut-outs. The geoboard allows students to use small rubber bands to form equivalent figures to those resulting in the psychomotor activity with the elastic bands. It provides continuity in terms of theoretical reflection to the fun activities.

Brousseau (1990) states that "Technology is understood as a set of knowledge with a scientific base that makes it possible to describe, explain, design and apply technical solutions to practical problems in a systematic and rational manner". Analyzing this, the importance of technology is evident today for the education of human beings; however, we should stress the need of students to interact with the resources in the environment, as these produce significant, long-lasting learning in any area of study.

Non-valid specified origin. He states that individuals learn through "Significant Learning", which is understood as the incorporation of the new information into the individual's cognitive structure. This will create an assimilation between the knowledge the individual possesses in his or her cognitive structure with the new information, facilitating learning".

These ideas are framed in the principles of globalization, interrelationships and the multidisciplinary nature of Basic Education, in relation to the disciplines of knowledge, particularly the interdisciplinary nature in the first two stages of Basic Education.

\section{Materials and methods}

For the execution of this scientific article, field research was conducted at the "Adolfo H. Simmonds" Educational Unit, where closed structured surveys were used that revealed the importance of drafting a procedural guide. The surveys were created based on a Likert scale, and the questions were written in simple language so that they were easily understood by the respondents.

Observation was also used to evidence the less-than-satisfactory characteristics of the students when learning geometry, as their lack of enthusiasm with learning was observed, as they are not stimulated with resources from their environment that motivate their knowledge in education for power and citizenship.

The scientific work methodology is that of applied field research based on direct observation; it will be applied in 2 research modes: field and bibliographic, based on the qualitative paradigm, as this makes it possible to obtain data and information found in books, on the Internet, in brochures and on posters.

The field research was applied by visiting "Adolfo H. Simonds" primary school, where this work originated. The intent of the project through this type of research is to solve the problems that exist in learning geometry, attempting to stress the importance of environmental resources in education for power and citizenship. Explanatory research served to determine the events and facts that have been explored in a specific time and place in order to indicate a true and definitive narration, which has made this research possible.

The population surveyed consisted of 57 parents, 60 students and 32 teachers. Information was gathered through surveys, which together with photographs and videos, made it possible to determine the elements 
necessary for its study and statistical analysis, which contributed to the materialization of valid information for this study.

\begin{tabular}{|c|l|c|}
\hline No. & \multicolumn{1}{|c|}{ Strata } & Population \\
\hline 1 & Teachers & 32 \\
\hline 2 & Students & 60 \\
\hline 3 & Legal representatives & 57 \\
\hline \multicolumn{2}{|c|}{ Total } & $\mathbf{1 4 9}$ \\
\hline
\end{tabular}

Table 1. Population (“Adolfo H. Simonds" educational unit)

\section{Results and discussion}

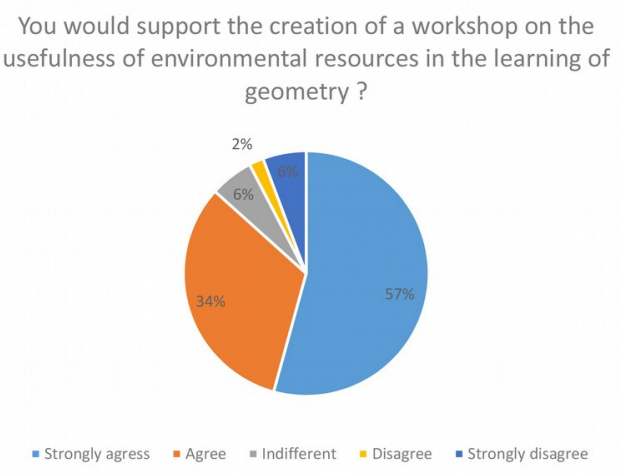

Figure 1. Creation of a workshop. Responses by parents, parent survey

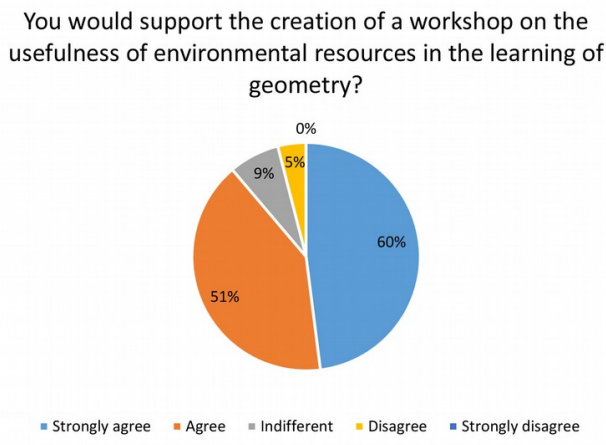

Figure 2. Creation of a workshop. Responses by students, student survey

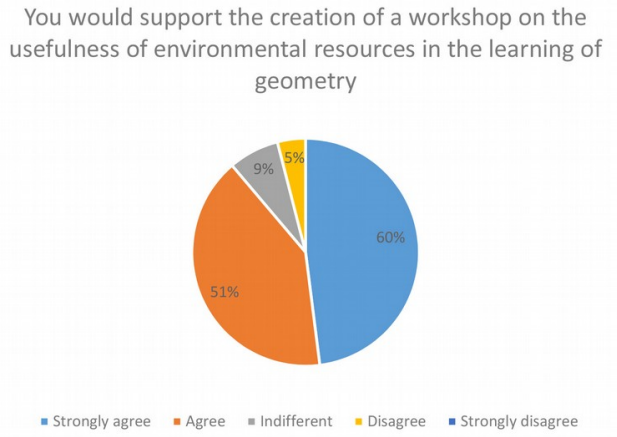

Figure 3. Creation of a workshop. Responses by teachers, teacher survey 
The analysis of the results is defined as satisfactory in order to be able to analyze the problematic situation this research presents, in this case, the lack of environmental resources applied to the learning of geometry in education for power and citizenship. The surveys demonstrate that $32 \%$ of the teachers surveyed strongly agree with the creation of the workshop on the usefulness of environmental resources in the learning of geometry as strategies in the learning process.

Furthermore, the survey expanded the information on the situation, as through observation it was possible to identify the problem: $60 \%$ of the students needed to use environmental resources to strengthen their learning of geometry in education for power and citizenship, since the traditional and technological methods did not fill the knowledge voids in caring, quality education.

Likewise, through the survey given to the parents, their concern was evident with regard to the learning of geometry by their children, as $57 \%$ strongly agree with the application of workshops to increase the use of environmental resources within the teaching-learning process.

\section{Conclusions}

The need for the teaching of geometry in the school setting corresponds firstly to the role geometry plays in daily life.

Basic geometric knowledge is essential to function in daily life: to orient oneself reflexively in space, to make estimates about shapes and distances, to make judgments and calculations related to the distribution of objects in space, among others.

Geometry is present in many areas of the production system of our societies today (industrial production, design, architecture, topography, among others). Education for power and citizenship needs to strengthen each of the areas of study, especially geometry, which currently does not meet the scope of significant learning due to the lack of application of teaching resources from the environment.

The educational environment needs workshops to find out about geometric shape, which is also an essential component of art, the visual arts and represents an important aspect in the study of the elements of nature, with it being crucial for reaching the goals of education for power and citizenship.

It is concluded that the application of this research is essential in order to identify the influence the use of environmental resources has on the learning of geometry in education for power and citizenship, which provides possible solutions to contribute to the development of better geometric concepts through recreational workshops.

\section{Declaration of Conflicting Interests}

The authors declared no potential conflicts of interest with respect to the research, authorship, and/or publication of this article.

\section{Funding}

The authors received no financial support for the research, authorship, and/or publication of this article.

\section{References}

Artigue, M. (2011). La educación matemática como un campo de investigación y como un campode práctica: Resultados, Desafíos. XIII conferencia interamericana de educación matemática. Recife, Brazil: CIAEM.

American Institutes for Research (AIR) (2005). What the United States can learn from Singapores world-class mathematics system: An exploratory study (and what Singapore can learn from the United States). Washington, DC: American Institutes for Research. 
Barber, M., \& Murshed, M. (2007). Cómo hicieron los sistemas educativos con mejor desempeño del mundo para alcanzar sus objetivos. McKinsey \& Co.

Brousseau, G. (1997). Theory of didactical situations in mathematics. Didactique des mathématiques, 1970-1990. Balacheff, N., Sutherland, R., \& Warfield, V. (Eds. and Trans.) Dordrecht: Kluwer Academic Publishers.

Brousseau, G. (1990). Le contrat didactique: Le milieu. Recherches en Didactique des Mathématiques, 9(3), 308-336.

Chevallard, Y. (2012). Teaching mathematics in tomorrow's society: A case for an oncoming counter paradigm (173-187). In Cho, S.J. (Ed.), The proceedings of the 12th International Congress on Mathematical Education.

Cantoral, R. (2014). El quehacer del matemático educativo: el pasaje del sujeto a su entorno. Revista Latinoamericana de Investigación en Matemática Educativa. 17(1), 5-6. https:/ / doi.org/10.12802/relime.13.1710

Espinoza, L., Barbé, J., \& Gálvez, G. (2011). Limitaciones en el desarrollo de la actividad matemática en la escuela básica: el caso de la aritmética escolar. Estudios Pedagógicos, 37(1), 105-125. https://doi.org/10.4067/S0718-07052011000100006

Espinoza, L., Barbé, J., \& Gálvez, G. (2009). Estudio de fenómenos didácticos vinculados a la enseñanza de la aritmética en la educación básica chilena. Enseñanz̧a de las Ciencias, 27(2), 157-168.

Gertler, P., Martínez, S., Premand, P., Rawlings, L., \& Vermeersch, C. (2011). La evaluación de impacto en la práctica. Washington, DC: International Bank for Reconstruction and Development/World Bank. https://doi.org/10.1596/978-0-8213-8681-1

Mullis, I.V.S., Martin, M.O., Foy, P., \& Arora, A. (2012). TIMSS 2011 International results in mathematics. Chestnut Hill, MA: TIMSS \& PIRLS International Study Center, Boston College.

Porlán, R., Rivero, A., \& Martín del Pozo, R. (1998). Conocimiento profesional y epistemología de los profesores II: estudios empíricos y conclusiones. Enseñanza de las Ciencias, 16(2), 271-288.

Singapore's Ministry of Education (2012). Primary mathematics teaching and learning syllabus. Singapore: Ministry of Education.

Published by OmniaScience (www.omniascience.com)

Journal of Technology and Science Education, 2018 (www.jotse.org)

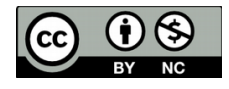

Article's contents are provided on an Attribution-Non Commercial 4.0 Creative commons International License. Readers are allowed to copy, distribute and communicate article's contents, provided the author's and JOTSE journal's names are included. It must not be used for commercial purposes. To see the complete licence contents, please visit https://creativecommons.org/licenses/by-nc/4.0/. 